\title{
Inhibition of the PI3K/AKT signaling pathway sensitizes diffuse large B-cell lymphoma cells to treatment with proteasome inhibitors via suppression of BAG3
}

\author{
TING YUAN ${ }^{1}$, FENG ZHANG ${ }^{1}$, XIANGXIANG ZHOU ${ }^{1}$, YING LI $^{1}$, \\ YA ZHANG $^{1}$, YANGYANG XU ${ }^{1}$ and XIN WANG ${ }^{1,2}$ \\ ${ }^{1}$ Department of Hematology, Shandong Provincial Hospital Affiliated to Shandong University, Jinan, Shandong 250021; \\ ${ }^{2}$ Institute of Diagnostics, School of Medicine, Shandong University, Jinan, Shandong 250012, P.R. China
}

Received January 12, 2018; Accepted January 25, 2019

DOI: $10.3892 / \mathrm{ol} .2019 .10029$

\begin{abstract}
Proteasome inhibitors represent a novel class of drugs that have clinical efficacy against hematological and solid cancer types, including acute myeloid leukaemia, myelodysplastic syndrome an non-small cell lung cancer. It has been demonstrated that the anti-apoptotic protein B-cell lymphoma-2-associated athanogene 3 (BAG3) is induced by proteasome inhibitors in various cancer cells and serves an important role in chemotherapy resistance. The phosphatidylinositol 3-kinase (PI3K)/RAC- $\alpha$ serine/threonine-protein kinase (AKT) pathway is constitutively activated in a number of lymphoid malignancy types, including diffuse large B-cell lymphoma (DLBCL) and Burkitt lymphoma. In the present study, the aim was to elucidate the role of the PI3K/AKT signaling pathway in the induction of BAG3, following exposure to a proteasome inhibitor in DLBCL cell lines. Bortezomib and MG132 were used as proteasome inhibitors. Western blotting was used to evaluate the roles of proteasome inhibitors and the PI3K/AKT pathway in BAG3 induction in DLBCL cells (LY1 and LY8), and LY294002 was used to block the PI3K/AKT pathway. Cell viability was detected using a Cell Counting Kit-8 assay. Apoptosis of LY1 and LY8 cells was quantified by Annexin V/7-amino-actinomycin D flow cytometry. The BAG3 protein was markedly induced upon exposure to bortezomib and MG132 in a dose-dependent manner. The
\end{abstract}

Correspondence to: Professor Xin Wang, Department of Hematology, Shandong Provincial Hospital Affiliated to Shandong University, 324 Jingwu Road, Jinan, Shandong 250021, P.R. China

E-mail: xinw007@126.com

Abbreviations: PI3K, phosphatidylinositol 3-kinase; BAG3, B-cell lymphoma-2-associated athanogene 3

Key words: diffuse large B-cell lymphoma, proteasome inhibitor, B-cell lymphoma-2-associated athanogene3, PI3K/RAC- $\alpha$ serine/ threonine-protein kinase pathway, proliferation
PI3K/AKT inhibitor LY294002 significantly suppressed the induction of BAG3 by proteasome inhibitors. Inhibition of the PI3K/AKT pathway decreased the proliferation and increased the apoptosis induced by proteasome inhibitors. The present results indicated that the PI3K/AKT pathway is associated with the activation of BAG3 expression in DLBCL cells, and is involved in the protective response against proteasome inhibition.

\section{Introduction}

Diffuse large B-cell lymphoma (DLBCL) is considered to be the most common subtype of non-Hodgkin lymphoma globally (1). In adults, DLBCL accountedfor 30-40\% of all cases of non-Hodgkin lymphoma worldwide until 2014 (2). Although significant advances have been made during the last few years in the treatment of DLBCL, particularly with immunochemotherapy, approximately one third of cases remain fatal according to a recent research in the United States in 2016, frequently due to chemotherapy resistance $(3,4)$. Therefore, continued investigations into novel therapeutic strategies are required.

Bortezomib is a proteasome inhibitor, a novel class of drugs that have antitumor activity, primarily through inhibition of the nuclear factor (NF)- $\kappa \mathrm{B}$ pathway. Additionally, it has been approved clinically for treatment of multiple myeloma and mantle cell lymphoma (5). Furthermore, a number of clinical trials have demonstrated that bortezomib has promising activity in patients with relapsed/refractory DLBCL (6-8). However, it may induce the expression of certain anti-apoptotic proteins, including heat shock protein 90 (9) and the antiapoptic Bcl-2 family member Mcl-1 (10), that could limit its antitumor efficacy. It has been demonstrated that B-cell lymphoma-2-associated athanogene 3 (BAG3), an anti-apoptotic molecule, is induced by proteasome inhibitors in various cancer cells, and BAG3 knockdown by small interfering RNA sensitizes cancer cells to proteasome inhibitor-induced apoptosis (11).

BAG3, also known as CAIR-1 or Bis, is a member of the BAG protein family. It contains a conserved domain and binds the ATPase domain of heat shock protein 70 (12). 
BAG3 mediates protein delivery to the proteasome, modulates apoptosis and serves a role in the processes of cell adhesion and migration (13). Evidence has indicated that BAG3 expression is upregulated in a number of cancer cell lines (14-20), including thyroid carcinoma, pancreatic cancer, prostate cancer, leukemic cells, ovarian cancer, neuroblastoma and glioblastoma. As reported, BAG3 acts as a pro-survival and anti-apoptotic protein in different cancer cells, and it underlies resistance to chemotherapy through decreasing the level of apoptosis $(14,15,18)$. Additionally, inhibition of BAG3 expression could potentiate the effectiveness of chemotherapy (21), indicating that BAG3 is a candidate therapeutic target of human cancer.

The phosphatidylinositol 3-kinase (PI3K)/RAC- $\alpha$ serine/threonine-protein kinase (AKT) pathway is constitutively activated in a number of lymphoid malignancy types, primarily by phosphorylation $(22,23)$. It has been implicated as serving crucial roles in the activation of growth and anti-apoptotic pathways (24). Overexpression of phosphorylated (p)-AKT is associated with a poor outcome in DLBCL $(22,25)$. Thus, the PI3K/AKT signaling pathway may represent a promising target for therapeutic intervention in DLBCL.

A number of studies reported that BAG3 may be induced by proteasome inhibitors, but this has not been investigated in DLBCL cell lines (26-28). It has been demonstrated that the anticancer effect of bortezomib is enhanced by PI3K/AKT pathway inhibitors in a number of tumor types, including myelodysplastic syndrome (29), hepatocellular carcinoma (30) and melanoma (31), however, this also has not been investigated in DLBCL. The present study therefore aimed to investigate whether proteasome inhibitors induce BAG3 in DLBCL cell lines, whether there is a synergistic anticancer effect between proteasome inhibitors and PI3K/AKT pathway inhibitors in DLBCL cell lines, and whether the synergy effect was due to the decreased expression of the anti-apoptotic protein BAG3. In the present study, it was demonstrated that the PI3K/AKT inhibitor LY294002 significantly suppressed the induction of BAG3 by proteasome inhibitors in DLBCL cell lines. It was further observed that inhibition of the PI3K/AKT pathway decreased the level of proliferation and increased the level of apoptosis induced by proteasome inhibitors. These results indicated that inhibition of the PI3K/AKT pathway could enhance sensitivity of DLBCL cells to proteasome inhibitors, at least partially, by suppression of BAG3 expression.

\section{Materials and methods}

Antibodies and reagents. Anti-BAG3 (dilution, 1:5,000; cat.no.ab92309), anti-AKT1 (dilution, 1:8,000; cat.no.ab32505) and anti-p-AKT1 (dilution, 1:8,000; cat. no. ab81283) were purchased from Abcam (Cambridge, UK). PI3K inhibitor LY294002 was obtained from Abcam. Proteasome inhibitor MG132 was obtained from Abmole Bioscience, Inc. (Houston, TX, USA). Proteasome inhibitor bortezomib was obtained from Xian-Janssen Pharmaceutical Ltd. (Shaanxi, China).

Cell culture. The human DLBCL cell lines LY1 and LY8 were provided by Professor B. Hilda Ye (Albert Einstein College of Medicine, New York, NY, USA), and were cultured in Iscove's modified Dulbecco's medium (IMDM; Gibco; Thermo Fisher
Scientific, Inc., Waltham, MA, USA) supplemented with $10 \%$ (vol/vol) fetal bovine serum (HyClone, Logan, UT, USA) at $37^{\circ} \mathrm{C}$ in a humidified atmosphere containing $5 \% \mathrm{CO}_{2}$. To analyze the effects of LY294002, MG132 and bortezomib on cell growth and expression of BAG3, LY1 and LY8 cells were cultured in the presence or absence of the drugs for $24 \mathrm{~h}$ at $37^{\circ} \mathrm{C}$, the working concentrations of LY294002 were 2.5, 5, 10,20 and $40 \mu \mathrm{M}$, the working concentrations ofbortezomib were $5,10,20,40$ and $80 \mathrm{nM}$, and the working concentrations of MG132 were $0.5,1,2,4$ and $8 \mu \mathrm{M}$. For experiments with LY294002 and proteasome inhibitor (bortezomib and MG132) treatments, LY1 and LY8 cells were pre-treated with LY294002 for $1 \mathrm{~h}$ prior to exposure to proteasome inhibitors.

Western blotting. Total protein was extracted by radioimmunoprecipitation assay buffer (Shenergy Biocolor Ltd., Shanghai, China), $1 \%$ phenylmethylsulfonyl fluoride and $1 \%$ phosphatase inhibitor. Protein concentrations were assessed using a Bicinchoninic Acid assay prior to loading the samples. Equal amounts of $40 \mu \mathrm{g}$ totalprotein was separated via $8 \%$ SDS-PAGE and transferred to polyvinylidene difluoride membranes (EMD Millipore, Billerica, MA, USA). Membranes were blocked at room temperature for $1 \mathrm{~h}$ with $5 \%$ defatted milk dissolved in tris-buffered saline containing $0.05 \%$ Tween-20 (TBST), and then membranes were incubated overnight at $4^{\circ} \mathrm{C}$ with primary antibodies against BAG3 (dilution, 1:5,000; cat. no. ab92309; Abcam), AKT1 (dilution, 1:8,000; cat. no. ab32505; Abcam) and pAKT1 (dilution, 1:8,000; cat. no. ab81283; Abcam). Membranes were washed with TBST followed by hybridized at room temperature for $1 \mathrm{~h}$ with the anti-rabbit and anti-mouse IgG horseradish peroxidase (HRP)-conjugated secondary antibodies (dilution, 1:1,000; cat. no. SPN-9001 and SPN-9002 respectively; OriGene Technologies, Inc., Beijing, China). Protein bandswere detected using an Enhanced Chemiluminescence Detection kit (EMD Millipore). GAPDH (dilution, 1:1,000; cat. no. TA-08; OriGene Technologies, Inc.) was used as the endogenous control.

Assessment of cell viability. The antiproliferative effects of LY294002 and proteasome inhibitors, alone or in combination, were determined using a Cell Counting Kit-8 (CCK-8; Beyotime Institute of Biotechnology, Haimen, China). Briefly, cells $\left(1 \times 10^{5}\right)$ were incubated in IMDM for $24 \mathrm{~h}$ at $37^{\circ} \mathrm{C}$ in a humidified atmosphere containing $5 \% \mathrm{CO}_{2}$, in triplicate, in a 96-well plate. LY294002 $(0,2.5,5,10,20$ and $40 \mu \mathrm{M})$, bortezomib $(0,5,10,20,40$ and $80 \mathrm{nM})$ and MG132 (0, 0.5, 1, 2, 4 and $8 \mu \mathrm{M}$ ) were then added to the cultures. After $24 \mathrm{~h}$ incubation at $37^{\circ} \mathrm{C}, 10 \mu \mathrm{l} \mathrm{CCK}-8$ was added to each well. After $24 \mathrm{~h}$ incubation at $37^{\circ} \mathrm{C}$ in a humidified atmosphere containing $5 \%$ $\mathrm{CO}_{2}$, the absorbance at a wavelength of $450 \mathrm{~nm}$ was measured. The percentage cell viability was calculated as follows: (A in experimental group - A in blank group/A in control group - A in blank group) x1 00\%.

Flow cytometric analysis. LY1 and LY8 cells were treated with LY294002 $(10 \mu \mathrm{M})$, or together with bortezomib $(40 \mathrm{nM})$ for $24 \mathrm{~h}$ at $37^{\circ} \mathrm{C}$, and then cells were harvested and the percentage apoptosis was measured by flow cytometry. Briefly, an aliquot of $1 \times 10^{5}$ cells was incubated with Annexin V-phycoerythrin 
A
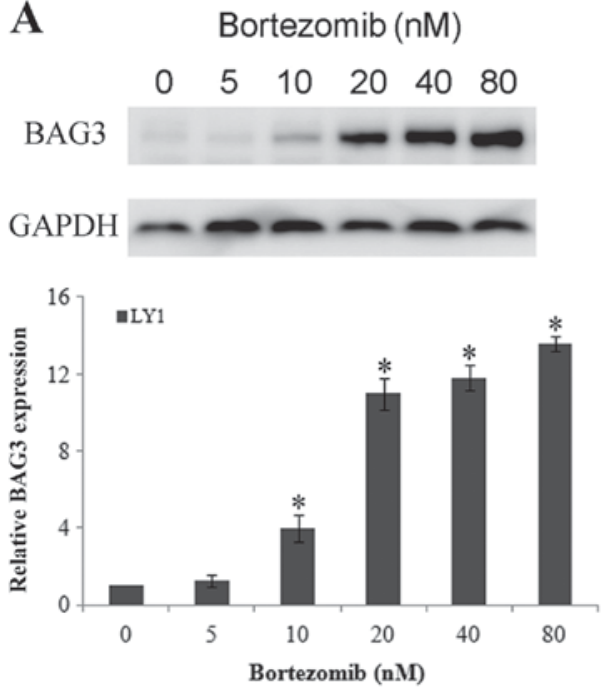

C
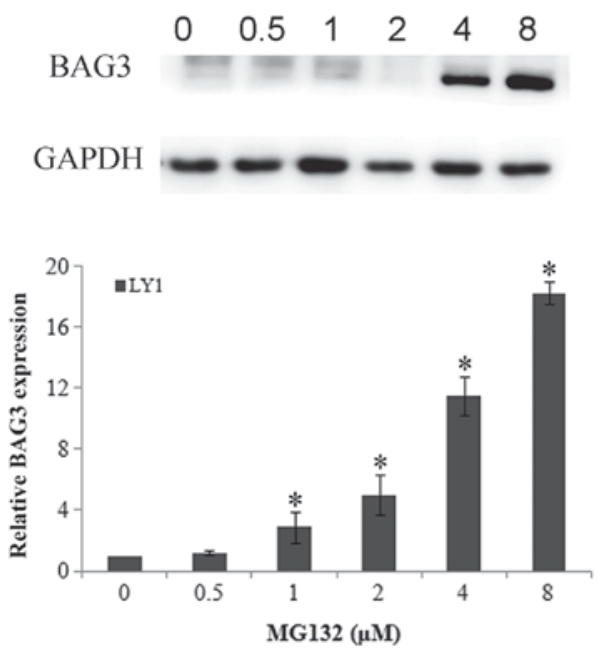

B

Bortezomib (nM)
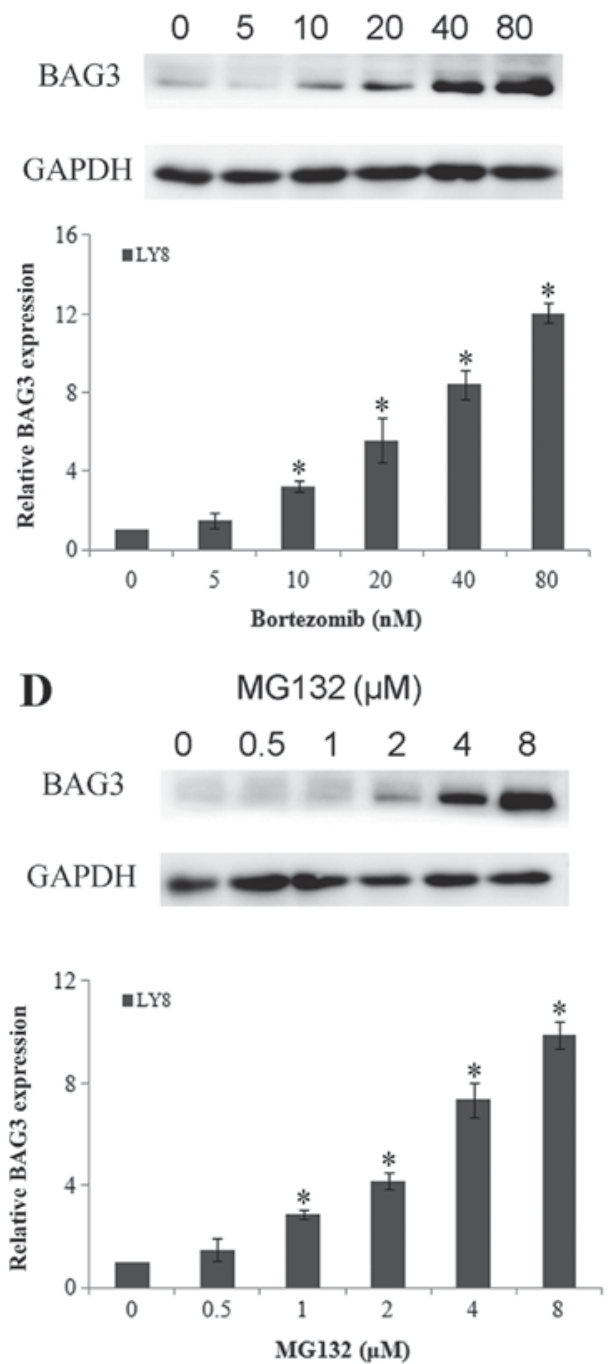

Figure 1. Effects of proteasome inhibition on the expression of BAG3. The BAG3 protein was induced by bortezomib and MG132 in a dose-dependent manner. (A) LY1 and (B) LY8 cells were incubated with bortezomib at different concentrations (0, 5, 10, 20, 40 and $80 \mathrm{nM})$. (C) LY1 and (D) LY8 cells were incubated with MG132 at different concentrations $(0,0.5,1,2,4$ and $8 \mu \mathrm{M})$. Protein lysates were analyzed by western blotting. Blots are representative of three individual experiments. The protein expression levels were normalized to those of GAPDH ("P $<0.05 \mathrm{vs.} 0 \mathrm{nM}$ bortezomib/0 $\mu \mathrm{M} \mathrm{MG132}$ ). BAG3, B-cell lymphoma-2-associated athanogene 3 .

and 7-amino-actinomycin D (7-AAD) for $15 \mathrm{~min}$ at room temperature in the dark, according to the manufacturer's protocols (BD Biosciences; Becton, Dickinson and Company, Franklin Lakes, NJ, USA). Subsequently, cells were immediately analyzed with a FACSCalibur flow cytometer (BD Biosciences; Becton, Dickinson and Company). The data were analyzed with FlowJo version 7.6 software (Tree Star, Inc., Ashland, OR, USA).

Statistical analysis. The software used for statistical analysis was SPSS for windows (version 17.0; SPSS, Inc., Chicago, IL, USA). Experiments were repeated at least three times. Data are expressed as the mean \pm standard deviation. The half-maximal inhibitory concentration $\left(\mathrm{IC}_{50}\right)$ values were analyzed with linear regression. Comparisons between groups of control and experimental were performed using one-way analysis of variance, and post hoc analysis was conducted with Fisher's least significant difference test.
$\mathrm{P}<0.05$ was considered to indicate a statistically significant difference.

\section{Results}

Effects of proteasome inhibitors on the expression of BAG3 in DLBCL cell lines. To investigate the effect of proteasome inhibitors on the expression of BAG3 in DLBCL cell lines, LY1 and LY8 cells were cultured in the presence or absence of different concentrations of bortezomib and MG132 for $24 \mathrm{~h}$. Bortezomib and MG132 are two different proteasome inhibitors, and the working concentration ranged from 5-80 nM for bortezomib and 0.5-8 $\mu \mathrm{M}$ for MG132. As depicted in Fig. 1, in the LY1 and LY8 cell lines, the BAG3 protein was significantly induced upon exposure to bortezomib (10, 20, 40 and $80 \mathrm{nM})$ and MG132 $(1,2,4$ and $8 \mu \mathrm{M})$ in a dose-dependent manner. It was observed that LY1 and LY8 cells exhibited a higher expression of BAG3 upon exposure to bortezomib (10, 20, 40 

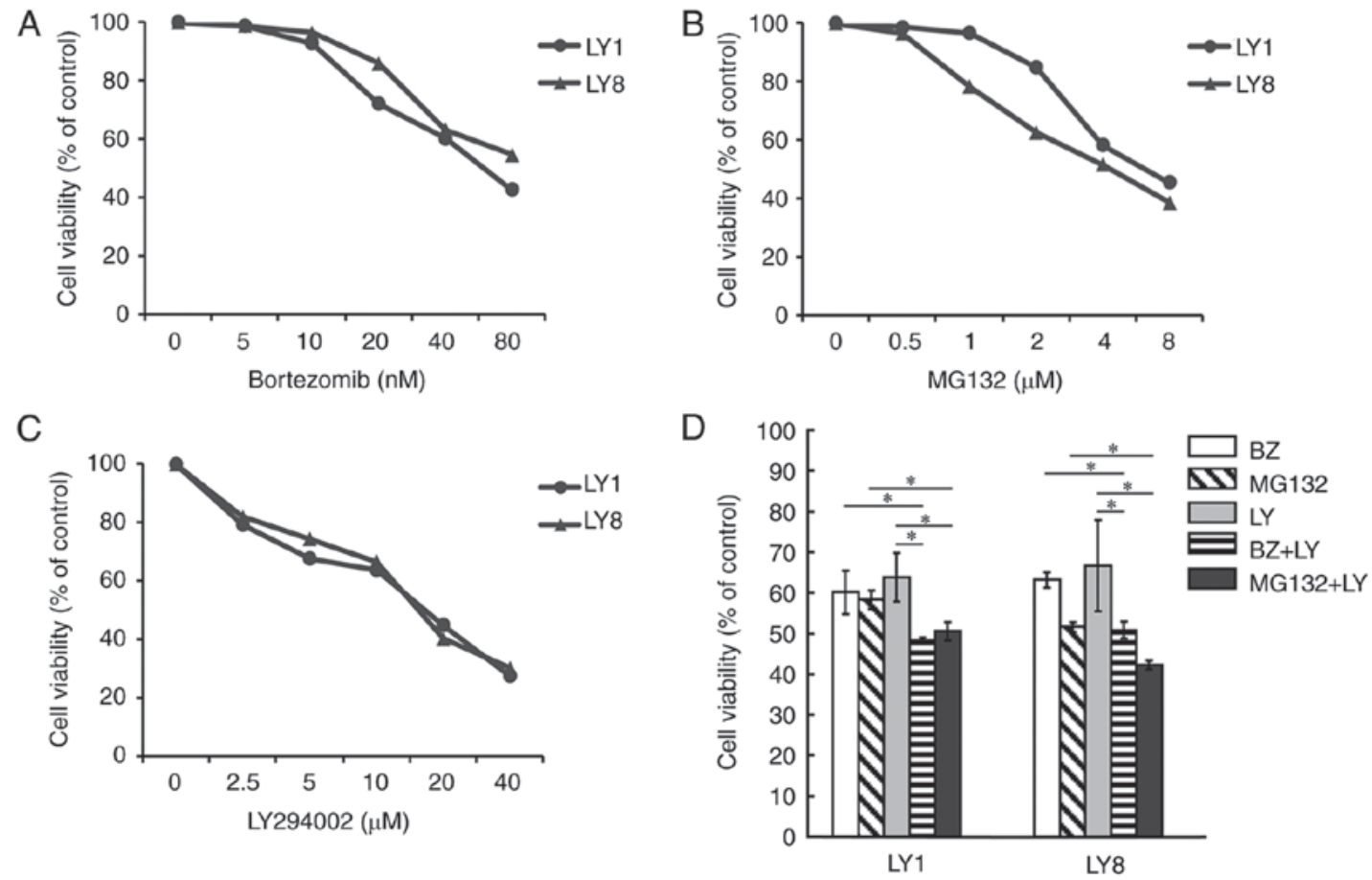

Figure 2. Effects of proteasome inhibition and phosphoinositide-3-kinase/RAC- $\alpha$ serine/threonine-protein kinase pathway inhibition on cell viability. Cell Counting Kit-8 assay was used to detect survival rates of LY1 and LY8 cells. Viability of LY1 and LY8 cells was inhibited with cultivation with (A) bortezomib, (B) MG132 and (C) LY294002 for $24 \mathrm{~h}$ in a concentration-dependent manner. LY1 and LY8 cells were pre-treated with LY294002 (10 $\mu \mathrm{M})$ for $1 \mathrm{~h}$, and then incubated with bortezomib (40 nM) or MG132 $(4 \mu \mathrm{M})$ for $24 \mathrm{~h}$. (D) Decreased cell viability was observed in proteasome inhibitors and LY294002 groups, compared with the single treatment group. Differences between 2 groups were compared by one-way analysis of variance followed by the least significant difference post hoc test ( $(\mathrm{P}<0.05)$. LY, LY294002; BZ, bortezomib.

and $80 \mathrm{nM})$ and MG132 $(1,2,4$ and $8 \mu \mathrm{M})$ compared with the control groups $(\mathrm{P}<0.05)$.

Effects of proteasome inhibitors and LY294002 on cell viability. Subsequently, it was determined whether the proteasome inhibitors and PI3K/AKT pathway inhibitor affect the DLBCL cell viability, and whether they have synergistic effects on cell death. The survival rates of LY1 and LY8 cells were measured with a CCK-8 assay. Fig. 2A-C depicts that cell viability was inhibited by bortezomib, MG132 and LY294002 in a concentration-dependent manner. The $\mathrm{IC}_{50}$ of bortezomib, MG132 and LY294002 in LY1 cells were $45 \mathrm{nM}$, 4.5 and $12 \mu \mathrm{M}$, respectively. In LY8 cells, the $\mathrm{IC}_{50}$ of bortezomib, MG132 and LY294002 were $42 \mathrm{nM}, 4.5$ and $13 \mu \mathrm{M}$, respectively. Therefore, $40 \mathrm{nM}$ bortezomib, $4 \mu \mathrm{M}$ MG132 and $10 \mu \mathrm{M}$ LY294002 were selected as the working concentrations for the following experiments. The PI3K/AKT pathway inhibitor LY294002 significantly decreased cell viability when used in combination with bortezomib and MG132 compared withseparate treatments (Fig. 2D; $\mathrm{P}<0.05$ ), indicating that the PI3K/AKT pathway has a role in the tolerance of DLBCL cells to proteasome inhibitors.

Role of PI3K/AKT inhibitor in proteasome inhibitor-induced BAG3 expression. To investigate whether the PI3K/AKT pathway was involved in the proteasome inhibitor-induced BAG3 expression in DLBCL cell lines, and to confirm whether the decreased cell viability effect of LY294002 with proteasome inhibitors was associated with the expression of the anti-apoptotic protein BAG3, the expression level of BAG3 was detected in LY1 and LY8 cells, which were pre-treated with LY294002 and then co-cultured with proteasome inhibitors for $24 \mathrm{~h}$. The AKT1 and p-AKT1 protein levels were detected by western blot analysis to represent the activation state of the PI3K/AKT pathway. The results of western blot analysis demonstrated that LY294002 notably suppressed the expression of BAG3 induced by proteasome inhibitors $(\mathrm{P}<0.05)$. The treatment with the proteasome inhibitors demonstrated no significant effect on relative $\mathrm{p}-\mathrm{AKT} 1$ protein expression levels, compared with the controls, whereas pre-treatment with LY294002 markedly reduced p-AKT1 protein levels (Fig. 3). The data indicated that the PI3K/AKT pathway was involved in the induction of BAG3 expression by proteasome inhibitors in DLBCL cell lines.

Bortezomib-induced apoptosis is promoted by LY294002. Subsequently, it was investigated whether PI3K/AKT inhibitor LY294002 affected the apoptotic response of DLBCL cells to bortezomib by flow cytometric analysis. Cells were incubated with LY294002 (10 $\mu \mathrm{M})$ for $1 \mathrm{~h}$ prior to exposure to bortezomib (40 nM), and then LY1 and LY8 cells were collected after $24 \mathrm{~h}$ to detect the apoptotic rate. The results are presented in Fig. 4. The levels of apoptosis were elevated in LY1 and LY8 cells when treated with LY294002 in combination with bortezomib, compared with the controls and the single treatment groups $(\mathrm{P}<0.05)$. In the bortezomib treated group, the apoptotic rates of LY1 and LY8 cells were 4.70 \pm 0.36 and $4.00 \pm 0.78 \%$, respectively, in the LY294002 treated group, the apoptotic rates of LY1 and LY8 cells were 3.57 \pm 2.51 and $3.73 \pm 1.20 \%$, respectively, and the percentage of apoptotic cells 

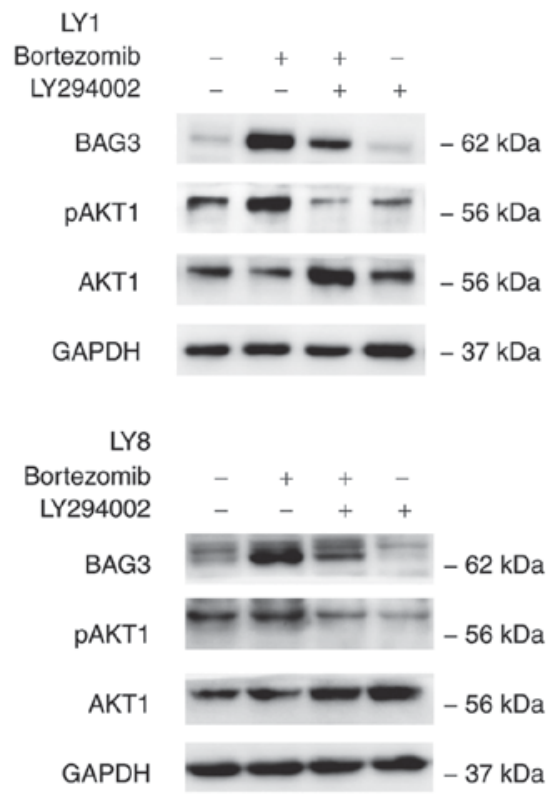
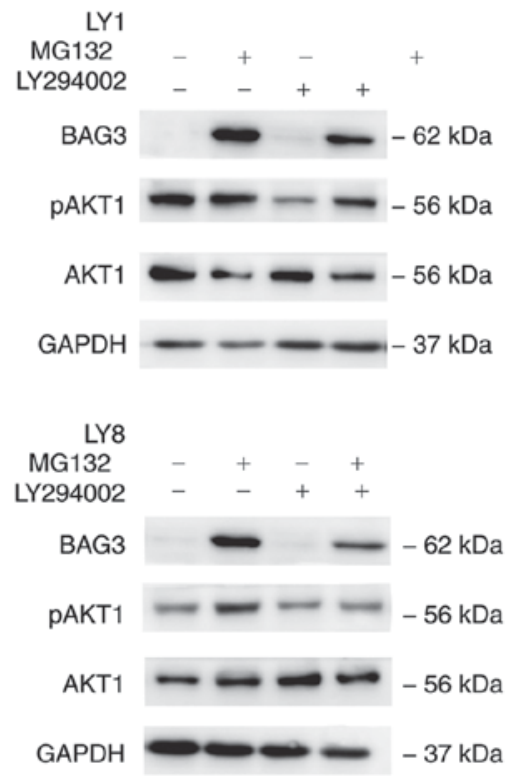
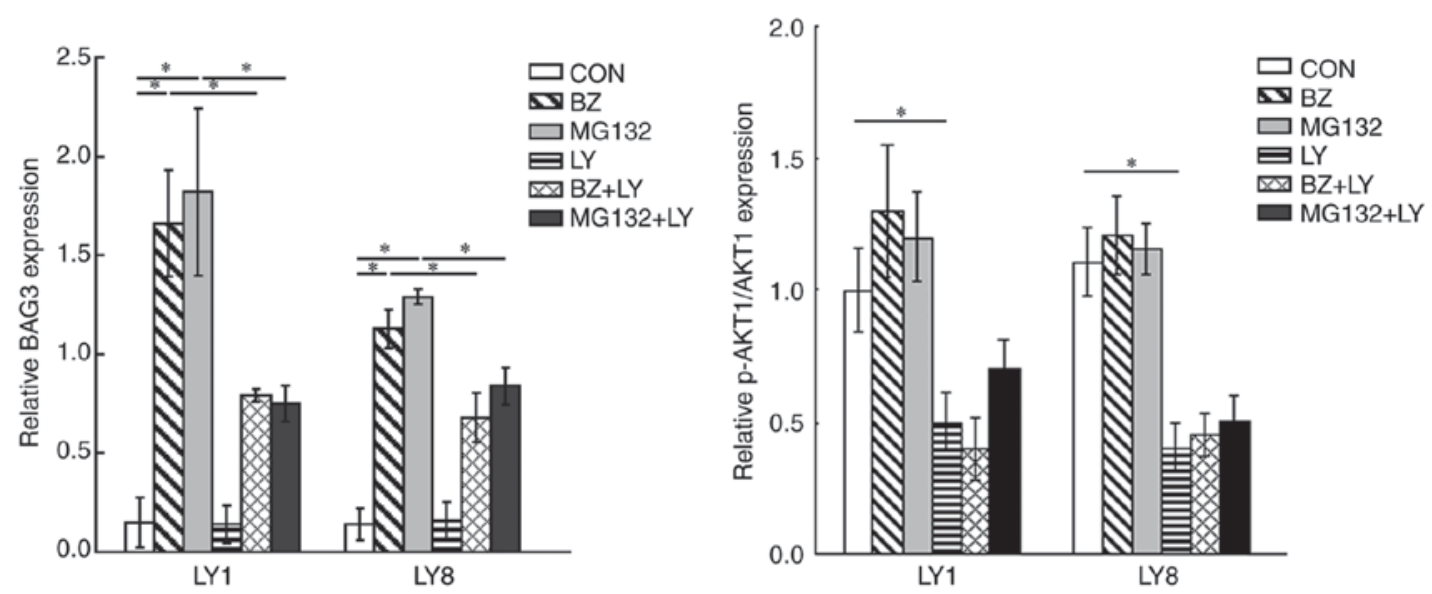

Figure 3. Effect of LY294002 on BAG3 expression induced by proteasome inhibitors. LY1 and LY8 cells were pre-treated with LY294002 (10 $\mu \mathrm{M})$ for $1 \mathrm{~h}$. The cells were then incubated with bortezomib $(40 \mathrm{nM})$ or MG132 $(4 \mu \mathrm{M})$ for $24 \mathrm{~h}$, and western blotting was performed. The results demonstrated that the phosphorylation of AKT1 was attenuated notably in LY1 and LY8 cells when pretreated with LY294002, and LY294002 suppressed the expression of BAG3 induced by proteasome inhibitors ("P<0.05). BAG3, B-cell lymphoma-2-associated athanogene 3; LY, LY294002; BZ, bortezomib.

in bortezomib+LY294002 group reached 7.70 \pm 0.56 (LY1) and $7.00 \pm 0.49 \%$ (LY8). The results indicated the sensitizing effects of LY294002 on the apoptotic responses of DLBCL cells to bortezomib.

\section{Discussion}

In the present study, it was observed that proteasome inhibitors activated the expression of BAG3 in DLBCL cells. The present data demonstrated that LY294002, a specific inhibitor of the PI3K/AKT pathway, significantly reduced BAG3 expression induced by proteasome inhibitors in DLBCL cells. The decreased expression of BAG3 was associated with reduced cell viability and increased apoptotic rate. Blockage of the PI3K/AKT pathway not only inhibited BAG3 expression, but also contributed to sensitivity of DLBCL cells to proteasome inhibitors. These data indicated that targeting the PI3K/AKT pathway could overcome resistance of DLBCL cells to proteasome inhibitors, partially through downregulation of BAG3 expression.
Proteasome inhibitors are emerging as a promising class of chemotherapeutic agents in the treatment of a variety of cancer types, including multiple myeloma, mantle cell lymphoma, acute myeloid leukaemia, myelodysplastic symdrome, non-small cell lung cancer and breast cancer (32-36). Their anticancer activities are performed through a number of cellular mechanisms, including induction of apoptosis, interference with cell cycle progression and inhibition of angiogenesis $(36,37)$. For DLBCL, data demonstrated that proteasome inhibitors, including bortezomib, inhibit constitutive NF- $\mathrm{\kappa B}$ activity and result in inhibition of cell proliferation via the induction of apoptosis in the activated DLBCL cells (38). However, in clinical trials, it has been observed that bortezomib alone has no significant notably increased response and median overall survival in activated B cell-like (ABC) DLBCL, compared with germinal center B cell-like (GCB) DLBCL (39). The results indicated that a number of unknown mechanisms could induce chemotherapy resistance of GBC DLBCL to proteasome inhibitors. 

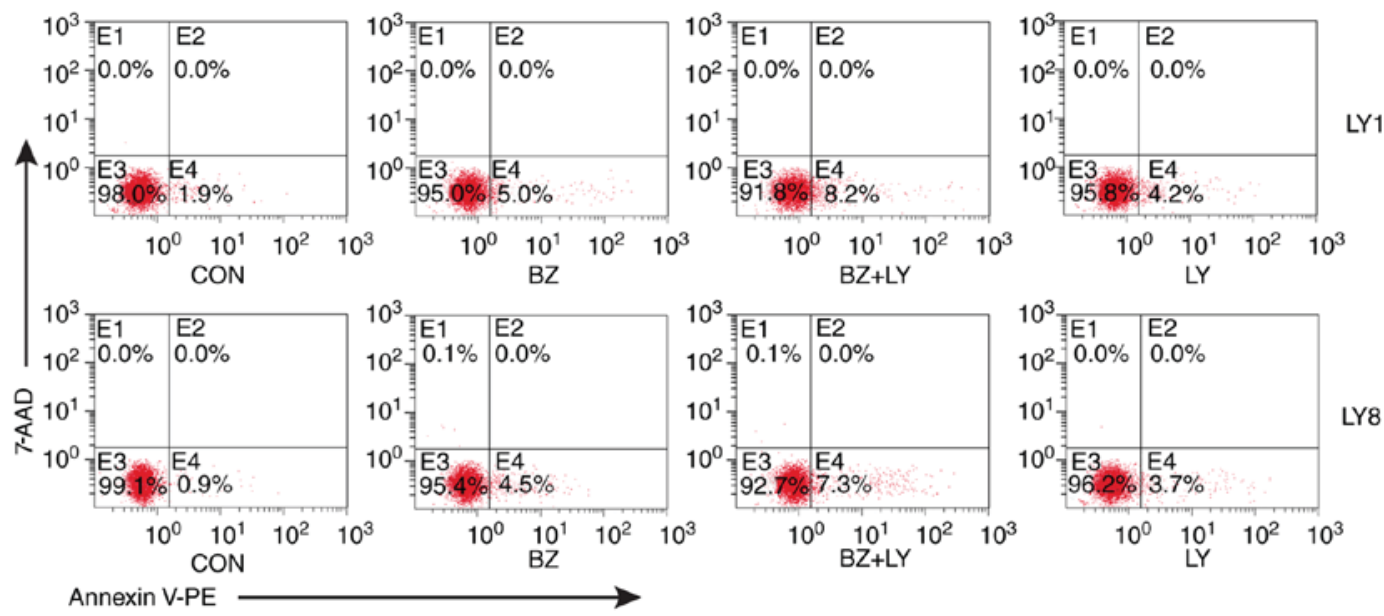

Annexin V-PE
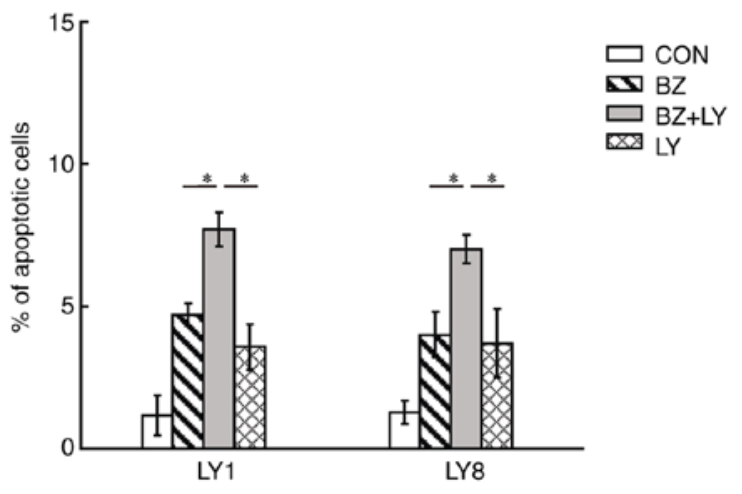

Figure 4. Effects of BZ and LY on cell apoptosis. LY1 and LY8 cells were pre-treated with LY $(10 \mu \mathrm{M})$ for $1 \mathrm{~h}$. The cells were then incubated with BZ $(40 \mathrm{nM})$ or MG132 $(4 \mu \mathrm{M})$ for $24 \mathrm{~h}$, and then apoptosis of LY1 and LY8 cells was quantified by Annexin V/7-AAD flow cytometry. Annexin V-positive cells were considered apoptotic. The results demonstrated that LY $(10 \mu \mathrm{M})$ enhanced the apoptotic responses of LY1 and LY8 cells to BZ (40 nM) ("P<0.05). LY, LY294002; BZ, bortezomib; 7-AAD, 7-amino-actinomycin D; PE, phycoerythrin.

In DLBCL, a synergistic effect of proteasome inhibitors combined with a number of novel agents has been demonstrated, including mechanistic target of rapamycin kinase inhibitors (40), the Bruton tyrosine kinase inhibitor (41) and the pan-histone deacetylase inhibitor (42). In multiple tumor models, including glioblastoma and mantle cell lymphoma, the anticancer ability of bortezomib has been demonstrated to be enhanced by combination with PI3K pathway inhibitors (43-46). For the first time, the synergy effect of bortezomib in combination with the PI3K/AKT pathway inhibitor LY294002 in DLBCL cells was elucidated.

Accumulating evidence indicated that BAG3, an anti-apoptotic protein, could be induced by proteasome inhibitors and may be responsible for the resistance to chemotherapy in various cell lines (14-20). It has been reported that bortezomib upregulates BAG3 expression in leukemic cells and BAG3 gene silencing notably potentiates the apoptosis level of this drug (21). Downregulation of BAG3 has been observed to increase cell death in response to proteasome inhibition in various cancer cells $(21,27,28)$. Collectively, these reports indicatedthat BAG3 induction is an unwanted molecular consequence of utilizing proteasome inhibitors to combat the malignant diseases, and thus may represent a potential therapeutic target for treating cancer with proteasome inhibitors.

In the present study, the mechanisms of chemoresistance of GCB DLBCL to proteasome inhibitors in the GCB DLBCL cell lines LY1 and LY8 was investigated, with the primary focus on the sensitizing effect of PI3K/AKT pathway inhibitor LY294002 to the proteasome inhibitors, and the association between the synergy effect and the expression level of the anti-apoptotic protein BAG3. Other investigators demonstrated the molecular mechanism of BAG3 upregulation induced by proteasome inhibitors $(26-28,47)$. It has been reported that heat shock transcription factor 1 is involved in BAG3 induction by proteasome inhibitor MG132 $(26,47)$. The c-Jun $\mathrm{N}$-terminal kinase pathway has been reported to be associated with the protective response against proteasome inhibition, by mediating induction of BAG3 (28). In rhabdomyosarcoma cells, NF- $\mathrm{KB}$-inducing kinase (NIK) is critical in mediating NF- $\mathrm{KB}$ activation and BAG3 induction upon co-treatment of cytoplasmic HDAC inhibitor and proteasome inhibitor (27). The present study revealed for the first time that inhibition of the PI3K/AKT signaling pathway enhanced sensitivity of DLBCL cells to proteasome inhibitors by suppression of BAG3 expression.

In the present study, there are various shortcomings. In addition to the conclusions drawn, it was determined that proteasome inhibitors have a tendency to activate the PI3K signaling pathway, but the result was not statistically significant. The results demonstrated that the two inhibitors had a synergistic effect that was statistically significant, but the synergistic effect was not notably pronounced. It is possible that alternative signaling pathways, including those involved in autophagy, may have been activated in response to combined 
treatment and may explain the observed reduction in cell viability. The exact mechanism by which BAG3 participates in the proteasome inhibitor induced expression and the PI3K signaling pathway requires further investigation.

In conclusion, the present data demonstrated that the PI3K/AKT pathway was associated with the activation of BAG3 expression in DLBCL cells and was involved in the protective response against proteasome inhibition. These results may have notable impact on the development of combined targeted approaches in DLBCL. Targeting BAG3 or the PI3K/AKT pathway combined with bortezomib may have an exciting anticancer effect for patients with GCB DLBCL. Additionally, animal, preclinical and clinical studies are required to validate the present results in future studies.

\section{Acknowledgements}

Not applicable.

\section{Funding}

The present study was partly supported by the National Natural Science Foundation (grant nos. 81473486 and 81270598), the Technology Development Projects of Shandong Province (grant no. 2014GSF118021), the Program of Shandong Medical Leading Talent, and the Taishan Scholar Foundation of Shandong Province.

\section{Availability of data and materials}

The datasets used and/or analyzed during the present study are available from the corresponding author on reasonable request.

\section{Authors' contributions}

TY and XW designed and guided the study. TY conducted all of the experiments. TY wrote and revised the manuscript. FZ, XZ, YL, YZ, and YX analyzed the obtained data. All authors read and approved the final manuscript.

\section{Ethics approval and consent to participate}

Not applicable.

\section{Patient consent for publication}

Not applicable.

\section{Competing interests}

The authors declare that they have no competing interests.

\section{References}

1. A clinical evaluation of the International Lymphoma Study Group classification of non-Hodgkin's lymphoma. The non-hodgkin's lymphoma classification project. Blood 89: 3909-3918, 1997.

2. McGuire S: World cancer report 2014. Geneva, Switzerland: World Health Organization, International Agency for Research on Cancer, WHO Press, 2015. Adv Nutr 7: 418-419, 2016.

3. Sarkozy C and Sehn LH: Management of relapsed/refractory DLBCL. Best Pract Res Clin Haematol 31: 209-216, 2018.
4. Teras LR, DeSantis CE, Cerhan JR, Morton LM, Jemal A and Flowers CR: 2016 US lymphoid malignancy statistics by World Health Organization subtypes. CA Cancer J Clin: Sep 12, 2016 (Epub ahead of print). doi: 10.3322/caac.21357.

5. Sharma A and Bhimji SS: Bortezomib. StatPearls [Internet]. Treasure Island (FL): StatPearls Publishing, Oct 27, 2018.

6. Camicia R, Winkler HC and Hassa PO: Novel drug targets for personalized precision medicine in relapsed/refractory diffuse large B-cell lymphoma: A comprehensive review. Mol Cancer 14: 207,2015

7. Yazbeck V, Shafer D, Perkins EB, Coppola D, Sokol L, Richards KL, Shea T, Ruan J, Parekh S, Strair R, et al: A phase II trial of bortezomib and vorinostat in mantle cell lymphoma and diffuse large B-cell lymphoma. Clin Lymphoma Myeloma Leuk 18: 569-575, 2018.

8. Evens AM, Rosen ST, Helenowski I, Kline J, Larsen A, Colvin J, Winter JN, van Besien KM, Gordon LI and Smith SM: A phase I/II trial of bortezomib combined concurrently with gemcitabine for relapsed or refractory DLBCL and peripheral T-cell lymphomas. Br J Haematol 163: 55-61, 2013.

9. Mitsiades CS, Mitsiades NS, McMullan CJ, Poulaki V, Kung AL, Davies FE, Morgan G, Akiyama M, Shringarpure R, Munshi NC, et al: Antimyeloma activity of heat shock protein-90 inhibition. Blood 107: 1092-1100, 2006.

10. Nencioni A, Hua F, Dillon CP, Yokoo R, Scheiermann C, Cardone MH, Barbieri E, Rocco I, Garuti A, Wesselborg S, et al: Evidence for a protective role of Mcl-1 in proteasome inhibitor-induced apoptosis. Blood 105: 3255-3262, 2005.

11. Wang HQ, Liu HM, Zhang HY, Guan Y and Du ZX: Transcriptional upregulation of BAG3 upon proteasome inhibition. Biochem Biophys Res Commun 365: 381-385, 2008.

12. Sondermann H, Scheufler C, Schneider C, Hohfeld J, Hartl FU and Moarefi I: Structure of a Bag/Hsc70 complex: Convergent functional evolution of Hsp70 nucleotide exchange factors. Science 291: 1553-1557, 2001.

13. Shi H, Xu H, Li Z, Zhen Y, Wang B, Huo S, Xiao R and Xu Z: BAG3 regulates cell proliferation, migration, and invasion in human colorectal cancer. Tumour Biol 37: 5591-5597, 2016.

14. Zhu H, Wu W, Fu Y, Shen W, Miao K, Hong M, Xu W, Young KH, Liu P and Li J: Overexpressed BAG3 is a potential therapeutic target in chronic lymphocytic leukemia. Ann Hematol 93: 425-435, 2014

15. Festa M, Del Valle L, Khalili K, Franco R, Scognamiglio G, Graziano V, De Laurenzi V, Turco MC and Rosati A: BAG3 protein is overexpressed in human glioblastoma and is a potential target for therapy. Am J Pathol 178: 2504-2512, 2011.

16. Gentilella A and Khalili K: BAG3 expression in glioblastoma cells promotes accumulation of ubiquitinated clients in an Hsp70-dependent manner. J Biol Chem 286: 9205-9215, 2011.

17. Liao Q, Ozawa F, Friess H, Zimmermann A, Takayama S, Reed JC, Kleeff J and Büchler MW: The anti-apoptotic protein BAG-3 is overexpressed in pancreatic cancer and induced by heat stress in pancreatic cancer cell lines. FEBS Lett 503: 151-157, 2001.

18. Romano MF, Festa M, Petrella A, Rosati A, Pascale M, Bisogni R, Poggi V, Kohn EC, Venuta S, Turco MC, et al: BAG3 protein regulates cell survival in childhood acute lymphoblastic leukemia cells. Cancer Biol Ther 2: 508-510, 2003.

19. Chiappetta G, Ammirante M, Basile A, Rosati A, Festa M, Monaco M, Vuttariello E, Pasquinelli R, Arra C, Zerilli M, et al: The antiapoptotic protein BAG3 is expressed in thyroid carcinomas and modulates apoptosis mediated by tumor necrosis factor-related apoptosis-inducing ligand. J Clin Endocrinol Metab 92: 1159-1163, 2007.

20. Staibano S, Mascolo M, Di Benedetto M, Vecchione ML, Ilardi G, Di Lorenzo G, Autorino R, Salerno V, Morena A, Rocco A, et al: BAG3 protein delocalisation in prostate carcinoma. Tumour Biol 31: 461-469, 2010.

21. Liu P, Xu B, Li J and Lu H: BAG3 gene silencing sensitizes leukemic cells to Bortezomib-induced apoptosis. FEBS Lett 583: 401-406, 2009.

22. Uddin S, Hussain AR, Siraj AK, Manogaran PS, Al-Jomah NA, Moorji A, Atizado V, Al-Dayel F, Belgaumi A, El-Solh H, et al: Role of phosphatidylinositol 3'-kinase/AKT pathway in diffuse large B-cell lymphoma survival. Blood 108: 4178-4186, 2006.

23. Fang X, Jiang Y, Feng L, Chen H, Zhen C, Ding M and Wang X: Blockade of PI3K/AKT pathway enhances sensitivity of Raji cells to chemotherapy through down-regulation of HSP70. Cancer Cell Int 13: 48, 2013. 
24. West KA, Castillo SS and Dennis PA: Activation of the PI3K/Akt pathway and chemotherapeutic resistance. Drug Resist Updat 5: 234-248, 2002.

25. Hasselblom S, Hansson U, Olsson M, Torén L, Bergström A, Nilsson-Ehle $\mathrm{H}$ and Andersson PO: High immunohistochemical expression of p-AKT predicts inferior survival in patients with diffuse large B-cell lymphoma treated with immunochemotherapy. Br J Haematol 149: 560-568, 2010.

26. Du ZX, Zhang HY, Meng X, Gao YY, Zou RL, Liu BQ, Guan Y and Wang HQ: Proteasome inhibitor MG132 induces BAG3 expression through activation of heat shock factor 1 . J Cell Physiol 218: 631-637, 2009.

27. Rapino F, Abhari BA, Jung M and Fulda S: NIK is required for NF- $\kappa$ B-mediated induction of BAG3 upon inhibition of constitutive protein degradation pathways. Cell Death Dis 6: e1692,2015.

28. Wang HQ, Liu BQ, Gao YY, Meng X, Guan Y, Zhang HY and Du ZX: Inhibition of the JNK signalling pathway enhances proteasome inhibitor-induced apoptosis of kidney cancer cells by suppression of BAG3 expression. Br J Pharmacol 158: 1405-1412, 2009.

29. Huang J, Ding T, Yang M, Liu H, Sun X and Jin J: Antitumor activity and drug interactions of proteasome inhibitor Bortezomib in human high-risk myelodysplastic syndrome cells Int J Hematol 93: 482-493, 2011

30. Chen KF, Yeh PY, Hsu C, Hsu CH, Lu YS, Hsieh HP, Chen PJ and Cheng AL: Bortezomib overcomes tumor necrosis factor-related apoptosis-inducing ligand resistance in hepatocellular carcinoma cells in part through the inhibition of the phosphatidylinositol 3-kinase/Akt pathway. J Biol Chem 284: 11121-11133, 2009.

31. Yeramian A, Sorolla A, Velasco A, Santacana M, Dolcet X, Valls J, Abal L, Moreno S, Egido R, Casanova JM, et al: Inhibition of activated receptor tyrosine kinases by Sunitinib induces growth arrest and sensitizes melanoma cells to Bortezomib by blocking Akt pathway. Int J Cancer 130: 967-978, 2012.

32. Ruggeri B, Miknyoczki S, Dorsey B and Hui AM: The development and pharmacology of proteasome inhibitors for the management and treatment of cancer. Adv Pharmacol 57: 91-135, 2009.

33. Crawford LJ, Walker B and Irvine AE: Proteasome inhibitors: A therapeutic strategy for haematological malignancy. Front Biosci 13: 4285-4296, 2008.

34. Park DJ and Lenz HJ: The role of proteasome inhibitors in solid tumors. Ann Med 36: 296-303, 2004.

35. Jones MD, Liu JC, Barthel TK, Hussain S, Lovria E, Cheng D, Schoonmaker JA, Mulay S, Ayers DC, Bouxsein ML, et al: A proteasome inhibitor, bortezomib, inhibits breast cancer growth and reduces osteolysis by downregulating metastatic genes. Clin Cancer Res 16: 4978-4989, 2010.

36. Manasanch EE and Orlowski RZ: Proteasome inhibitors in cancer therapy. Nat Rev Clin Oncol 14: 417-433, 2017.
37. Voorhees PM and Orlowski RZ: The proteasome and proteasome inhibitors in cancer therapy. Annu Rev Pharmacol Toxicol 46: 189-213, 2006

38. Bu R, Hussain AR, Al-Obaisi KA, Ahmed M, Uddin S and Al-Kuraya KS: Bortezomib inhibits proteasomal degradation of $\mathrm{I} \kappa \mathrm{B} \alpha$ and induces mitochondrial dependent apoptosis in activated B-cell diffuse large B-cell lymphoma. Leuk Lymphoma 55: 415-424, 2014

39. Dunleavy K, Pittaluga S, Czuczman MS, Dave SS, Wright G, Grant N, Shovlin M, Jaffe ES, Janik JE, Staudt LM, et al: Differential efficacy of bortezomib plus chemotherapy within molecular subtypes of diffuse large B-cell lymphoma. Blood 113: 6069-6076, 2009.

40. Wright JJ: Combination therapy of bortezomib with novel targeted agents: An emerging treatment strategy. Clin Cancer Res 16: 4094-4104, 2010.

41. Dasmahapatra G, Patel H, Dent P, Fisher RI, Friedberg J and Grant S: The Bruton tyrosine kinase (BTK) inhibitor PCI-32765 synergistically increases proteasome inhibitor activity in diffuse large-B cell lymphoma (DLBCL) and mantle cell lymphoma (MCL) cells sensitive or resistant to bortezomib. Br J Haematol 161: 43-56, 2013.

42. Fenske TS, Shah NM, Kim KM, Saha S, Zhang C, Baim AE, Farnen JP, Onitilo AA, Blank JH, Ahuja H, et al: A phase 2 study of weekly temsirolimus and bortezomib for relapsed or refractory B-cell non-Hodgkin lymphoma: A wisconsin oncology network study. Cancer 121: 3465-3471, 2015.

43. Yu W, Chen Y, Xiang R, Xu W, Wang Y, Tong J, Zhang N, Wu Y and Yan H: Novel phosphatidylinositol 3-kinase inhibitor BKM120 enhances the sensitivity of multiple myeloma to bortezomib and overcomes resistance. Leuk Lymphoma 58: 428-437, 2017.

44. Qu FL, Xia B, Li SX, Tian C, Yang HL, Li Q, Wang YF, Yu Y and Zhang YZ: Synergistic suppression of the PI3K inhibitor CAL-101 with bortezomib on mantle cell lymphoma growth. Cancer Biol Med 12: 401-408, 2015.

45. Lin L, Gaut D, Hu K, Yan H, Yin D and Koeffler HP: Dual targeting of glioblastoma multiforme with a proteasome inhibitor (Velcade) and a phosphatidylinositol 3-kinase inhibitor (ZSTK474). Int J Oncol 44: 557-562, 2014.

46. Kim A, Park S, Lee JE, Jang WS, Lee SJ, Kang HJ and Lee SS: The dual PI3K and mTOR inhibitor NVP-BEZ235 exhibits anti-proliferative activity and overcomes bortezomib resistance in mantle cell lymphoma cells. Leuk Res 36: 912-920, 2012.

47. Franceschelli S, Rosati A, Lerose R, De Nicola S, Turco MC and Pascale M: Bag3 gene expression is regulated by heat shock factor 1. J Cell Physiol 215: 575-577, 2008. International (CC BY-NC-ND 4.0) License. 